\title{
O RELATIVISMO CULTURAL E O HOMICÍDIO DE CRIANÇAS INDÍGENAS NO BRASIL
}

\section{CULTURAL RELATIVISM AND HOMICIDE OF INDIGENOUS CHILDREN IN BRAZIL}

LUCAS TABANEZ MURTA SOUZA

Graduando em Direito, modalidade Integral - Escola Superior Dom Helder Câmara, Belo Horizonte - MG. Email: lucatmurta@gmail.com.

CAIO AUGUSTO SOUZA LARA Mestre e Doutor em Direito pela Faculdade de Direito da Universidade Federal de Minas Gerais - UFMG. Professor da Escola Superior Dom Helder Câmara. Pesquisador Associado ao Programa RECAJ-UFMG - Acesso à Justiça e Solução de Conflitos. Secretário de Comunicação do Conselho Nacional de Pesquisa e Pósgraduação em Direito - CONPEDI. Belo Horizonte-MG. E-mail: caiolarabh@yahoo.com.br.

\section{RESUMO}

O tema-problema da pesquisa que se pretende desenvolver é o relativismo cultural como pretexto para a negligência do Estado brasileiro frente ao homicídio de crianças indígenas. É importante salientar que o princípio da tolerância é um argumento sedutor que pode ser utilizado tanto para ação quanto para a negligência. Por essa razão, Melly afirma que "quando países elevam práticas culturais, é comumente para justificar seu fracasso em suportar os termos do tratado" (MELLY, 2003, p.68, tradução nossa). Logo, a tradição do homicídio de criança com deficiência em várias tribos brasileiras acaba por negar, muitas vezes, a própria prática cultural, 
Personalidade Acadêmica Homenageada:

Raymundo Juliano Feitosa (Universidade Federal do Rio Grande do Norte - UFRN)

tornando-se um paradoxo: perpetuar a cultura e negá-la simultaneamente. Portanto, tem-se a pergunta fundamental: a cultura pode excluir os indígenas da proteção do ordenamento jurídico brasileiro e internacional? A partir de reflexões sobre o tema, pondera-se que o relativismo cultural se tornou um ponto importante para a efetivação da livre determinação dos povos. Entretanto, alguns membros da sociedade internacional utilizam de tal argumento para negar direitos fundamentais à sua população. Observa-se que o Estado brasileiro, ao deixar de intervir em comunidades indígenas que praticam o homicídio de crianças, trata as crianças indígenas de forma diferente do restante da população. Doravante, o objetivo do trabalho é analisar do ponto de vista da antropologia, da filosofia e da ciência jurídica se os atos de homicídio de crianças realizados por algumas tribos indígenas devem ou não serem punidas no Poder Judiciário oficial e se há a devida observância dos Direitos Humanos pelo fato de não fazerem parte da cultura e valores ocidentais. A pesquisa que se propõe pertence à vertente metodológica jurídico-sociológica. No tocante ao tipo de investigação, foi escolhido, na classificação de Witker (1985) e Gustin (2010), o tipo jurídico-projetivo. O raciocínio desenvolvido na pesquisa será predominantemente dialético. De acordo com a técnica de análise de conteúdo, afirma-se que trata-se de uma pesquisa teórica, o que será possível a partir da análise de conteúdo dos textos doutrinários, normas e demais dados colhidos na pesquisa. Após do exposto concluise preliminarmente que, apesar de, segundo Kyrillos (2013, p. 102), haver uma suposta superação do paradigma do sincretismo dos povos indígenas, é possível abstrair, de acordo com dados do Conselho Indigenista Missionário (2017, p.117), a falta de dignidade dessa população, sendo 42 casos de desassistência em 2017. Dessa forma, é fácil olvidar a cidadania brasileira dos indígenas, que é assegurada pela Constituição. Não custa lembrar que a lei maior, em seu artigo $4^{\circ}$, inciso II (BRASIL, 1988), estabelece a prevalência dos Direitos Humanos. Logo, os autóctones brasileiros são defendidos pelo Direito brasileiro e o Direito Internacional. A partir disso, uma das respostas possíveis ao delicado problema jurídico, é que sendo a cultura parte inerente à essência e, considerando os índios parte integrantes da categoria humana, é lícito inferir, por um viés existencialista ateu, que o homem não tem uma essência anterior a sua existência (SARTRE, 1943, p.8). Em outras palavras, 
Personalidade Acadêmica Homenageada:

Raymundo Juliano Feitosa (Universidade Federal do Rio Grande do Norte - UFRN)

permitir o homicídio de crianças indígenas é permitir o julgamento de uma cultura estranha ao indivíduo, promovendo, por consequência, apenas uma morte exordial e não um ritual benéfico para o espírito daquele ser. Não obstante, criar sanções e substituir a negligência estatal por uma intervenção total não ajudará na resolução do problema. Por essa razão, faz-se mister o estudo aprofundado da cultura das tribos praticantes do homicídio de crianças, a fim de se propor a criação de um sistema de adoção integrado ao povo a fim de solucionar o problema sem a imposição cultural.

PALAVRAS-CHAVES: Homicídio de Crianças; Indígenas; Relativismo Cultural; Negligência Estatal.

\section{REFERÊNCIAS}

ALESSI, Gil. Bebê morto com tiro na cabeça é um cruel símbolo da situação dos povos indígenas no Brasil. EI País. Disponível em: https://bit.ly/2xJsYMj. Acesso em: 04 mai. 2019.

BOOBIO, Norberto. A era do Direito. Tradução: Carlos Nelson Coutinho. Brasil, Rio de Janeiro. Título original: L'età dei Diritti. Elsevier, 1992. Disponível em: https://edisciplinas.usp.br/pluginfile.php/297730/mod_resource/content/0/norbertobobbio-a-era-dos-direitos.pdf. Acesso em: 04 mai. 2019.

BRASIL. Constituição da República Federativa do Brasil de 1988. Disponível em: http://www.planalto.gov.br/ccivil_03/constituicao/constituicao.htm. Acesso em: 30 abr. 2019.

CONSELHO INDIGENISTA MISSIONÁRIO. Violência contra povos indígenas no Brasil, 2017. Disponível em: https://cimi.org.br/wpcontent/uploads/2018/09/Relatorio-violencia-contra-povos-indigenas_2017-Cimi.pdf. Acesso em: 04 mai. 2019.

GUSTIN, Miracy Barbosa de Sousa; DIAS, Maria Tereza Fonseca. (Re)pensando a pesquisa jurídica: teoria e prática. 3ㄹ. ed. Belo Horizonte: Del Rey, 2010.

KYRILLOS, Gabriela de Morais. Política Indigenista no Brasil: Passado assimilacionista, futuro emancipatório? Revista Jurídica - UNICURITIBA, Curitiba, v.1 n.30, p. 91-111, 2014. Disponível em: https://bit.ly/2JyA9OW. Acesso em: 20 mai. 2019. 
Personalidade Acadêmica Homenageada:

Raymundo Juliano Feitosa (Universidade Federal do Rio Grande do Norte - UFRN)

MELLY, Sally Engle. Human Rights Law and the Demonization of Culture(And Antropology Along the Way). Wellesley College, Wellesley, mai. 2003. Disponível em: https://anthrosource.onlinelibrary.wiley.com/doi/pdf/10.1525/pol.2003.26.1.55.

Acesso em: 04 de abr. 2019.

SARTRE, Jean-Paul. O existencialismo é um humanismo. Tradução: Rita Correia Guedes. França, Paris. Título original: L'existentialisme est un humanisme. Les Edition Nagel, 1970. Disponível em: https://bit.ly/1L3k4aL. Acesso em: 04 mai. 2019.

SARTRE, Jean-Paul. O ser e o nada. Tradução: Paulo Perdigão. Brasil, Petrópolis. Título original: L'être et le nédant - Essai d'ontologie phénoménologique. Vozes, 2007. Disponível em: http://www.netmundi.org/home/wp-content/uploads/2017/07/O-Ser-eo-Nada-texto.pdf. Acesso em: 04 mai. 2019.

WITKER, Jorge. Como elaborar una tesis en derecho: pautas metodológicas y técnicas para el estudiante o investigador del derecho. Madrid: Civitas, 1985. 